\title{
A Compact Flexible Frequency Reconfigurable Antenna for Heterogeneous Applications
}

\author{
NIAMAT HUSSAIN', STUDENT MEMBER, IEEE, WAHAJ ABBAS AWAN², STUDENT \\ MEMBER, IEEE, SYEDA IFFAT NAQVI ${ }^{3 *}$, ADNAN GHAFFAR ${ }^{4}$, STUDENT MEMBER, IEEE, \\ ABIR ZAIDI ${ }^{5}$, SYED AFTAB NAQVI ${ }^{6 \ltimes}$, ADNAN IFTIKHAR ${ }^{7}$, MEMBER, IEEE, XUE JUN \\ $\mathrm{LI}^{4}$, SENIOR MEMBER, IEEE \\ ${ }^{1}$ Department of Computer and Communication Engineering, Chungbuk National University, South Korea. \\ ${ }^{2}$ Department of Integrated IT Engineering, Seoul National University of Science and Technology, Seoul, South Korea \\ ${ }^{3}$ Telecommunication Engineering Department, University of Engineering and Technology Taxila, Punjab, Pakistan \\ ${ }^{4}$ Department of Electrical and Electronic Engineering, Auckland University of Technology, Auckland, New Zealand \\ ${ }^{5}$ Department of Electrical Engineering, Laboratory EEA \& TI, Hassan II University, Casablanca, Morocco \\ ${ }^{6}$ Department of Electrical and Computer Engineering, COMSATS University Islamabad, Sahiwal Campus, Pakistan \\ ${ }^{7}$ Department of Electrical and Computer Engineering, COMSATS University Islamabad, Pakistan \\ Corresponding author: *Syeda Iffat Naqvi (email:iffat.naqvi@uettaxila.edu.pk ) and ${ }^{\text {a }}$ Syed Aftab Naqvi (e-mail: aftabnaqvi@cuisahiwal.edu.pk)
}

\begin{abstract}
This paper presents a compact frequency reconfigurable antenna for flexible devices and conformal surfaces. The antenna consists of a simple easy to fabricate structure consisting of a stub loaded circular radiator, designed on commercially available RT5880 flexible substrate $\left(\varepsilon_{\mathrm{r}}=2.2\right)$ with a thickness of $0.254 \mathrm{~mm}$. The combination of stub loading and slot etching techniques are utilized to achieve the advantages of compactness, frequency reconfigurability, wide impedance bandwidth, and stable radiation pattern with structural conformability. The frequency reconfigurability is achieved by employing two p-i-n diodes. Simulated and experimental results showed that the antenna operates in various important commercial bands, such as S-band ( $2 \mathrm{GHz}-4 \mathrm{GHz})$, Wi-Max $(3.5 \mathrm{GHz}$ and $5.8 \mathrm{GHz}), \mathrm{Wi}-\mathrm{Fi}(3.6 \mathrm{GHz}, 5 \mathrm{GHz}$, and $5.9 \mathrm{GHz}), 5 \mathrm{G}$ sub-6-GHz $(3.5 \mathrm{GHz}$ and $4.4 \mathrm{GHz}-5 \mathrm{GHz})$, and ITU-band $(7.725 \mathrm{GHz}-8.5 \mathrm{GHz})$ with the additional advantages of structural conformability. Furthermore, the performance comparison of the proposed flexible antenna with the state-of-the-art flexible antennas in terms of compactness, frequency reconfigurability, and number of operating bands demonstrates the novelty of the proposed antenna and its potential application in heterogeneous applications.
\end{abstract}

INDEX TERMS CPW-fed, Conformability, frequency reconfigurable, heterogeneous applications, miniaturized, multiband, portable, wideband

\section{INTRODUCTION}

Recently, the world has witnessed a rapid revolution in the wireless communication industry due to the pressing demand to reach more users while maintaining a reliable communication system meeting the end-user requirements. As a result, a series of modern applications and standards have emerged including fifth generation (5G) of communication, internet of things (IoT), big data applications, and vehicular communications, etc. [1]. However, these emerging technologies are posing new challenges with respect to radio spectrum congestion and have overlapped allocation of wireless frequency bands. The phenomenon of antenna reconfigurability for its promising characteristic of tuning the operating frequency for the desired applications has made its marks to handle such challenges [2].

On the other hand, flexible electronic technology is classified among the most interesting research area in today's world due to the rapid increase in demand of flexible wireless electronic devices like wearables, vehicles sensors, and conformal structure etc. [3]. Moreover, the flexible antennas have over-performance compared to rigid devices, in terms of compactness, flexibility, durability, lightweight, and energy efficiency [4]. However, the antenna designers working on flexible antennas must address some challenges, including the shift of the resonant frequency and degradation impedance mismatch due to the variation of effective capacitance during bending of the antenna [5]. In addition, the proximity of the antenna to human tissue imposes other 
constraints such as gain reduction and the disruption of the antenna impedance matching [6-7].

Other than the reconfiguration and flexibility characteristics, the antenna compactness is highly appreciated as the miniaturized antennas significantly reduce the size of electronic systems [8]. Therefore, the combination of flexibility with compactness makes the antennas preferable for modern communication systems and devices [9]. Several low-profile, compact single-band, multi-band reconfigurable antennas [10,11], and UWB flexible antennas are reported in the literature [12-20]. However, modern flexible devices demand operation at multiple frequency bands, robust band switching, and compactness in a single antenna [21]. Thus, the applications of the above-mentioned antennas may become limited.

In [21-22], CPW fed quad-band and penta-band antennas were reported. The work proposed in [21] shows the compact size and more bands as compared to reported work in [22], however, the use of copper tape instead of practical diodes do not provide efficient results and limits their application for practical applications. Another CPW fed tri-band antenna is presented in [23]. Although the results reported were in good agreement with simulations, however, the antenna presents a larger size along with an insufficient number of operating bands. On the other hand, the reported work in [24] has the advantage of multimode functionality i.e. wideband mode and two dual-band modes, but the working frequency range of the antenna is from $2 \mathrm{GHz}$ to $4 \mathrm{GHz}$, which is not suitable for UWB applications. In [25], a high gain dual band frequency reconfigurable antenna is presented. The high gain is achieved by compromising on antenna size, which limits its application for compact devices.

Another interesting work is reported in [26], where researchers used two varactor diodes to achieve continuous frequency reconfigurability. Besides the disadvantage of narrowband and larger dimensions, it also has the disadvantage of high cost due to newly developed material. In [27], a monopole antenna is presented where the main radiator is connected with an $L$-shaped and $U$-shaped radiator using p-i-n diode. Depending upon the state of the diode, the antenna can resonate in single-band or dual-band operating mode. Although the antenna is compact but still the working frequency range is not suitable for many applications including UWB applications. To sum up the above discussion: A lot of work on the flexible and reconfigurable antennas has been done. However, the design of a single antenna having the advantages of maximum operating bands, wide operating frequency range, and a high level of compactness is still a challenge for researchers working in the area of flexible antennas.

In this paper, a compact, flexible, and multi-band CPWfed slotted circular patch antenna is presented. The antenna is loaded with a rectangular stub for bandwidth enhancement. Two slots are etched on the circular radiator structure to achieve a multi-mode and multi-band behavior with the help of two p-i-n diodes. The presented antenna operates in dualband and tri-band mode by varying the basing state of the two diodes. The major contribution of this work can be some up as:

- The presented antenna offers significant compactness with the additional advantages of multiband mode and frequency reconfigurability as compared to the state-ofthe-art works.

- To the best of authors' knowledge, this is the first antenna of its kind operating at a wide frequency band ranging $2.05-10.7 \mathrm{GHz}$.

- Besides a moderate gain, wide bandwidth, and low return loss characteristics, the antenna also exhibits consistent results in both rigid and bending conditions. This makes the antenna suitable for modern flexible devices like wearables, vehicle sensors, etc.

The rest of the paper is organized as follows. The design methodology of the antenna is described in Section II. The comparison of the simulated and measured results is presented in Section III along with a brief comparison with the most recent works reported in the literature. Finally, the article is concluded in Section IV.

\section{THEORY AND DESIGN METHODOLOGY OF THE PROPOSED ANTENNA}

The schematic of the proposed frequency reconfigurable antenna is shown in Fig. 1 (a-c). The antenna is etched on top side of a thin ROGERS RT5880LZ substrate having thickness $(h)=0.254 \mathrm{~mm}$, relative permittivity $\left(\varepsilon_{r}\right)=2.1$ and dissipation constant $(\tan \delta)=0.002$. Thin substrates are famous to design compact microwave circuity due to the tightly bound fields at the cost of relatively narrow bandwidth [28]. Coplanar waveguide (CPW) feeding technique as compared to other feeding techniques create extra modes and has less quality factor $(\mathrm{Q})$, thus results in wide and multiband resonances [29-34]. Therefore, in this work, CPW feed is used to excite the radiating circular patch to achieve multiband resonance in proposed slotted circular patch antenna [35].

The resonating frequency $f_{\mathrm{o}}$ of the overall circular radiator is calculated by using equation given in [36]:

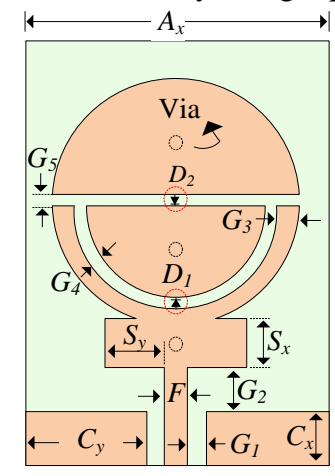

(a)

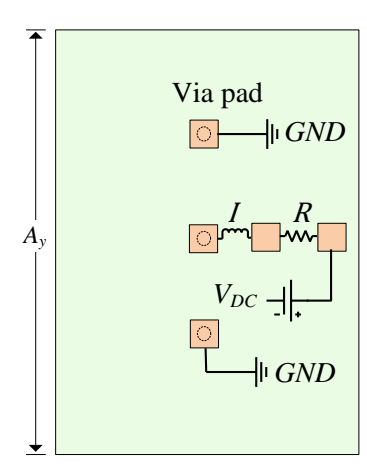

(b)

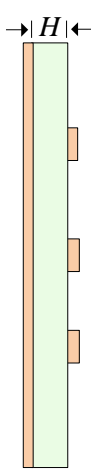

(c)
FIGURE 1. Schematic of the proposed antenna (a) top-view (b) bottom view showing the incorporation of pads for biasing circuitry, and (c) side-view 


$$
\mathrm{f}_{o}=\frac{1.8412 \times c}{4 \pi R_{\text {req }} \sqrt{\varepsilon_{r}}}
$$

where $c$ is the speed of the light and $R_{\text {req }}$ is the effective radius of the circular patch which is calculated using:

$$
R_{\text {req }}=R_{o} \sqrt{1+\frac{2 H}{\pi \varepsilon_{r} R_{o}}\left(\ln \left(\frac{\pi R_{o}}{2 H}\right)+1.7726\right)}
$$

where $H$ is the thickness of the substrate, $R_{o}$ is the radius of the monopole, and $\varepsilon_{r}$ is the relative permittivity of the substrate. For $5.4 \mathrm{GHz}$ resonating frequency, the optimized value of $R_{o}=11 \mathrm{~mm}$ is obtained. Next, the rectangular stub having dimension $S_{x} \times S_{y}$ is placed between the feed line and the circular radiator to enhance the narrow bandwidth of the antenna. The enhancement in the bandwidth is observed due to the introduction of extra reactive load by the stub which significantly improved matching between feedline and radiator over wide bandwidth [8]. The impedance bandwidth $\left(\left|\mathrm{S}_{11}\right|<-10 \mathrm{~dB}\right)$ of the conventional antenna is found to be $350 \mathrm{MHz}(2.25 \mathrm{GHz}-2.6 \mathrm{GHz})$ which corresponds to a fractional bandwidth of $14.6 \%$. Whereas the insertion of rectangular stub resulted in two passbands of $2.48 \mathrm{GHz}-3.28 \mathrm{GHz}$ and $4.94 \mathrm{GHz}-9.58$ GHz, as depicted in Fig. 2.

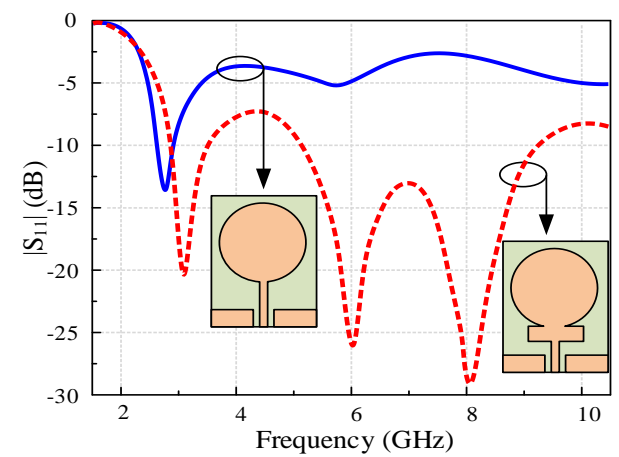

FIGURE 2. Scattering parameter $\left(\left|\mathrm{S}_{11}\right|(\mathrm{dB})\right)$ comparison among conventional narrowband antenna and wideband antenna with a single notch band due to rectangular stub.

Subsequently, a semicircular slot having an internal gap of $G_{4}$ is inserted in the radiator. The insertion of this slot resulted in the mitigation of a wide band spectrum (2.9-7.7 $\mathrm{GHz}$ ) from the operating region. The inner radius $R_{\text {in }}$ of this slot is calculated using the relation:

$$
R_{\text {in }} \approx L_{\text {slot }} / \pi,
$$

where $L_{\text {slot }}$ is the effective length of the slot which is numerically calculated by the following equation given in [37]:

$$
L_{\text {slot }}=\frac{c}{2 f_{r} \sqrt{\varepsilon_{e f f}}}
$$

where $f_{r}$ is the central frequency and $\varepsilon_{e f f} \approx \frac{\varepsilon_{r}+1}{2}$. For the presented case, the $f_{r}$ is chosen to be $5.2 \mathrm{GHz}$ and the simulated optimized value of $R_{i n}=8 \mathrm{~mm}$ is achieved. The gap $G_{4}$ is responsible for controlling the bandwidth of the notched frequency and it could be adjusted as per requirements of the system. Wider the gap, the wider will be the notch band region. However, $1 \mathrm{~mm}$ inner gap is selected for the present scenario which is equal to the physical dimension of the RF p-i-n diode (model \# SMP1345 (SC-79)). Next, a rectangular slot is etched on the radiator to add additional capacitive effects in the antenna, which resulted in the improvement of impedance matching ranging from $3.28 \mathrm{GHz}-4.94 \mathrm{GHz}$. Thus, a UWB antenna having an impedance bandwidth of $6.39 \mathrm{GHz}(2.91 \mathrm{GHz}-$ $9.3 \mathrm{GHz}$ ) is designed. The width of the rectangular slot is chosen to be $1 \mathrm{~mm}$ as well, for the placement of the diode. The effects of the semicircular and rectangular slots, in terms of S-parameter are compared in Fig. 3.

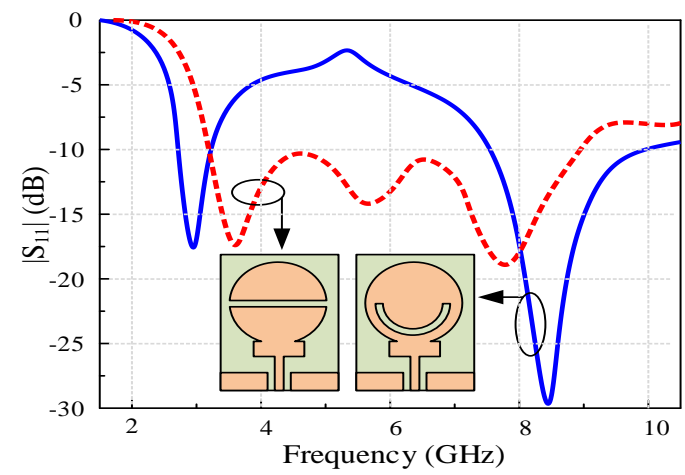

FIGURE 3. S-parameters $\left(\left|S_{11}\right|(d B)\right)$ comparison among various antenna topologies.

Finally, both dual-band and wide-band antennas are integrated to form a single multi-band antenna. The evolution of the proposed antenna providing capability of dual- and wide-band responses is shown in Fig. 4. Afterword, two p-i-n diodes, $D_{1}$ and $D_{2}$ are deployed in the slots of the circular patch to connect and disconnect the different parts with feeding structure to get multi-mode characteristics. Commercially available finite element method based High-Frequency Structure Simulator (HFSS) is used to simulate the proposed antenna. The optimized antenna parameters obtained after design methodology explained above are: $A_{x}=35 \mathrm{~mm}, A_{y}=25 \mathrm{~mm}, C_{x}=5 \mathrm{~mm}$, $C_{y}=11 \mathrm{~mm}, S_{x}=5.8 \mathrm{~mm}, S_{y}=3.85 \mathrm{~mm}, H=0.254 \mathrm{~mm}, F$ $=1.8 \mathrm{~mm}, G_{1}=2 \mathrm{~mm}, G_{2}=1 \mathrm{~mm}, G_{3}=0.6 \mathrm{~mm}, G_{4}=1$ $\mathrm{mm}$, and $G_{5}=1 \mathrm{~mm}$.

In simulation environment, parallel lumped RLC model with values of $R, L$, and $C$ shown in Figure $5(a-b)$ are

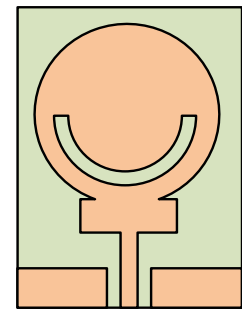

Dual-band antenna FIGURE 4. Various step

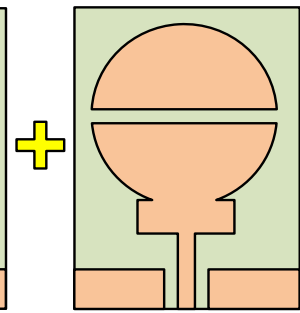

Wide-band antenna

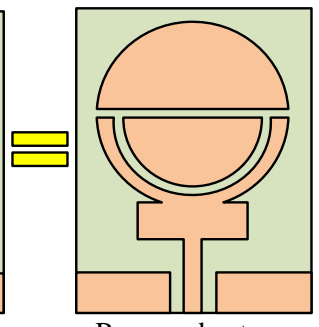

Proposed antenna 
used to mimic diodes $\mathrm{ON}$ and $\mathrm{OFF}$ states. In addition, via and padding on the back sides of the proposed antenna as shown in Figure 1 (b) are also modeled in the simulation environment to achieve consistent simulation and measurement results. It can be seen from Figure 5 (a) that in ON state, equivalent circuit having a series combination of $4.7 \Omega$ resistor and $0.15 n H$ inductor is modeled using parallel RLC boundary conditions. On the other hand, in OFF state, a series combination of $0.15 \mathrm{nH}$ with a parallel combination of $7 \mathrm{~K} \Omega$ resistor and $0.017 \mathrm{pF}$ capacitor, as depicted in Figure 5(b) is modeled using RLC boundary conditions.

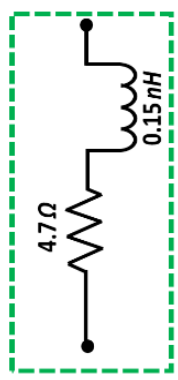

(a)

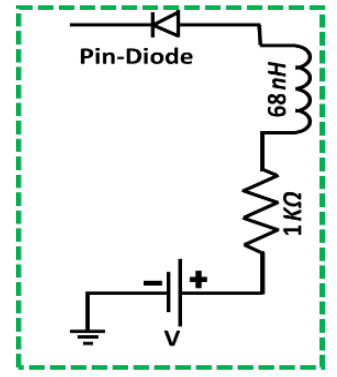

(c)
FIGURE 5. Equivalent model of diode for (a) switch ON state (b) switch OFF state (c) detailed biasing circuit.

The utilization of ON and OFF states of p-i-n didoes change the electrical length of the radiator to allow the appropriate flow of current density. The ON and OFF states of $\mathrm{p}$-i-n diodes consequently matched the impedance at different frequency bands at a time and resulted in frequency reconfigurability at multiband depending upon the RF current flowing in the resonating structures.

\section{SIMULATED AND EXPERIMENTAL RESULTS}

\section{A. MEASUREMENT SETUP}

To verify the simulated results, a prototype of the simulated antenna with optimized dimensions shown in Fig. 1 is fabricated and tested. A commercially available $50 \Omega$ SMA connector is utilized to feed the antenna and Skyworks p-i-n diodes having model \# SMP-1345 (SC-79) are soldered to connect three different conducting patches of the radiator.

To provide biased voltage for $\mathrm{p}-\mathrm{i}-\mathrm{n}$ diode operation, extra paddings as shown in Fig. 1 (b) and modeled in simulation environment are also etched on the bottom side of substrate. A photograph of the fabricated prototype with pads and via connection is shown in Fig. 6 (a). In particular, on the back side of the proposed antenna, the upper and lower end of the circular radiator is connected to ground through conducting via. A stable voltage $V_{D C}$ is provided to the middle part of the radiator via the $V_{D C}$ pad connected to the biasing circuitry of the diodes. A detailed description of the biasing circuit is shown in Fig. 5 (c). Fig. 5 (c) presents the configuration of biasing circuit where $1 \mathrm{~K} \Omega$ resistor is used to limit the amount of DC current coming from source $\mathrm{V}_{\mathrm{DC}}=3 \mathrm{~V}$, while $68 \mathrm{nH}$ blocks the unnecessary flow of RF current towards diode. The inductor selected was low profile chip inductor 0402CT (1005), part number: 0402CT - 12NX-RW. The inductor behaved as RF choke, while thin copper wires connected the antenna biasing structure with a $3 \mathrm{~V}$ battery, as shown in Figure 6 (a). For $\left|S_{11}\right|(d B)$ measurements, calibrated Vector Network Analyzer (VNA) is utilized, whereas broadband standard horn antenna is used for far-field measurements inside fully calibrated anechoic chamber, as depicted in Figure 6 (b).
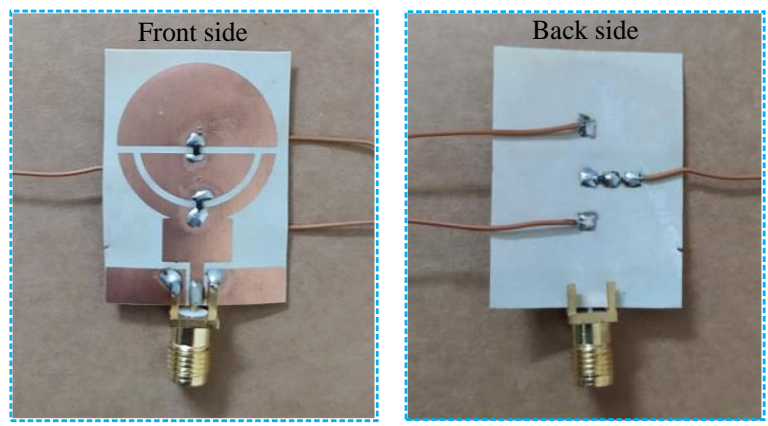

(a)

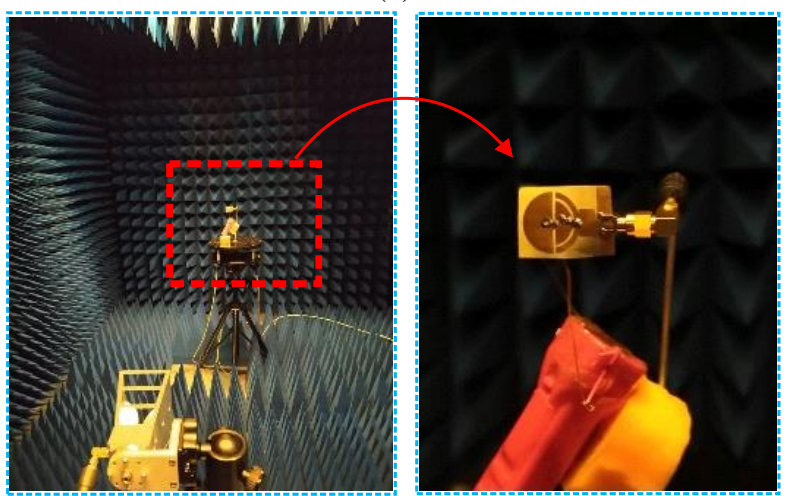

(b)

FIGURE 6. Photographs of the (a) fabricated prototype of the proposed antenna and (b) measurement setup for the farfield measurements.

\section{B. SCATTERING PARAMETERS}

Fig. 7 (a-c) illustrates the comparison between simulated and measured $\left|\mathrm{S}_{11}\right|(\mathrm{dB})$ results. For the ease of understanding, the ON state of the diode is represented by ' 1 ' while diode in OFF state is represented by ' 0 '. The three possible combinations of diodes are used; case- 00 , case-10, and case-11, where first and second digit shows the switching state of $D_{1}$ and $\mathrm{D}_{2}$, respectively. The antenna exhibits three passbands for case-10, while dual passbands are observed for case-00 and case- 11 . Figure 7 (a) shows that for case-00, the simulated impedance bandwidth for the two operating bands is $3.06 \mathrm{GHz}-6.17 \mathrm{GHz}$ and $7.1 \mathrm{GHz}-8.95 \mathrm{GHz}$, while measured values for case-00 are found to be $2.52 \mathrm{GHz}-6.02 \mathrm{GHz}$ and $7.1 \mathrm{GHz}-10.7$ GHz. Similarly, Fig. 7 (b) depicts the results for case-10. The three operating bands achieved in simulations are from 2.77 $\mathrm{GHz}-3.6 \mathrm{GHz}, 4.28 \mathrm{GHz}-5.98 \mathrm{GHz}$, and $7.1-8.9 \mathrm{GHz}$. However, $2.82 \mathrm{GHz}-3.56 \mathrm{GHz}, 4.32 \mathrm{GHz}-5.91 \mathrm{GHz}$, and $7.4 \mathrm{GHz}-9.4 \mathrm{GHz}$ bands are achieved in measurements. 


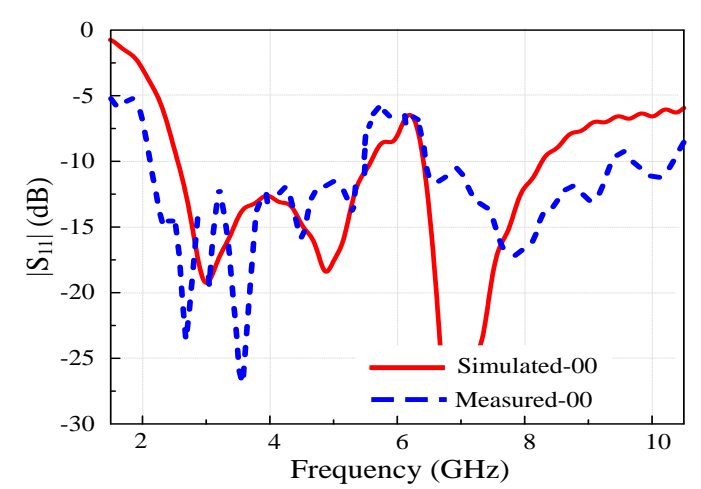

(a)

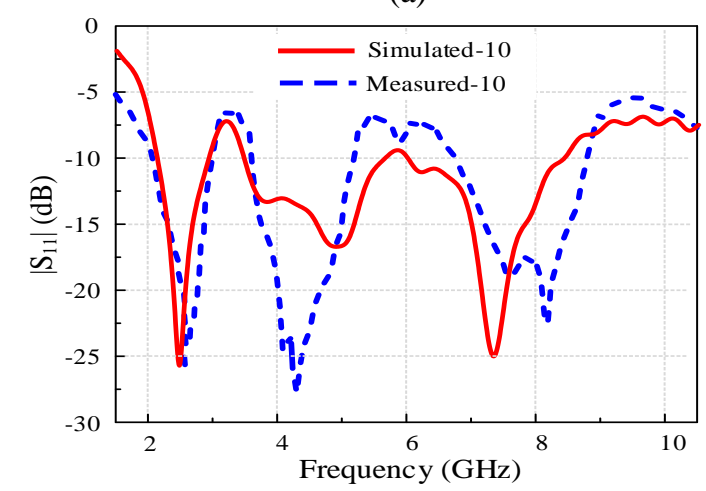

(b)

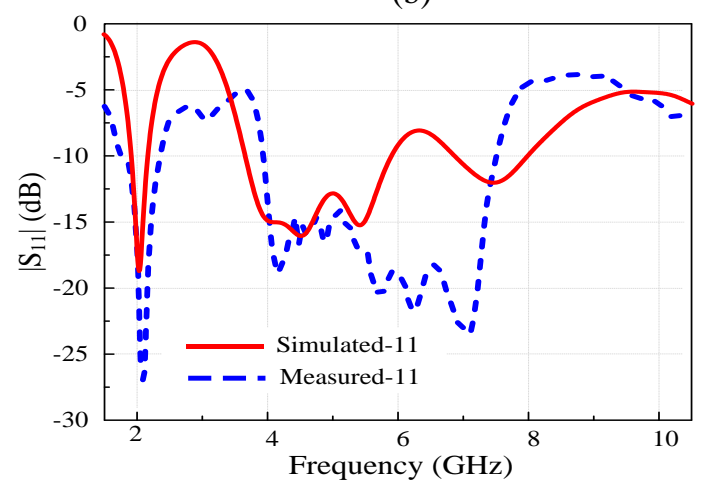

(c)

FIGURE 7. $\left|\mathrm{S}_{11}\right|(\mathrm{dB})$ comparison of the proposed antenna for various diode states (a) case-00 (b) case-10 (c) case-11.

Contrarily, dual-band response is achieved for case-11. In simulations, the impedance bandwidth of the dual-band is from
$2.05 \mathrm{GHz}-2.36 \mathrm{GHz}$ and $3.87-8.3 \mathrm{GHz}$, as shown in Figure 8 (c). Whereas a slight variation in impedance bandwidth of the is observed i.e. $1.98 \mathrm{GHz}-2.51 \mathrm{GHz}$ and $3.97 \mathrm{GHz}-7.87$ GHz, as illustrated in Fig. 7 (c). The slight difference between simulated and measured results shown in Figure $7(\mathrm{a}-\mathrm{c})$ is attributed to the change in inductance because of fabrication imperfections, soldering, vias platting, and connector losses.

\section{SURFACE CURRENT DISTRIBUTION}

To provide a better understanding of the multiband behavior of the proposed antenna using various $p-i-n$ diodes states, the surface current density for different switching states at various frequencies are presented in Fig. 8. For OFF state of both diodes $D_{1}$ and $D_{2}$ referred as case-00, the current density is maximum across feedline, rectangular stub, and semicircular portion, as shown Fig. 8 (a) and (b). This results in broad bandwidth around $3.5 \mathrm{GHz}$ because of current density in rectangular stub and semi-circular patch, whereas other resonance at around $8 \mathrm{GHz}$ is attributed to rectangular stub which corresponds to lower electrical length. Results of $\left|S_{11}\right|$ (dB) shown in Fig. 7 (a) confirm the dual-band operation when both diodes are switched OFF (case-00). For case-10 (when diode $D_{l}$ is $\mathrm{ON}$ and $D_{2}$ is $\mathrm{OFF}$ ), the surface current is distributed across rectangular stub attached with semicircular stub and middle semi-circular patch, as depicted in Fig. 8 (b-d). The mutual coupling effect and flow of RF current because of the $D_{l}$ ON state, three resonances at 3.1 $\mathrm{GHz}, 5.2 \mathrm{GHz}$, and $9 \mathrm{GHz}$ are achieved. $5.2 \mathrm{GHz}$ and $9 \mathrm{GHz}$ resonances are because of the lower portion directly connected to feed, whereas third resonance i.e. $3.1 \mathrm{GHz}$ is due to middle semi-circular patch and lower patch portion. Similarly, for case-11, when both diodes are in ON state, all the patches are connected which results in larger electrical length and showed resonance at $2.1 \mathrm{GHz}$, However, resonance at $6 \mathrm{GHz}$ is achieved due to the lower portion and mutual coupling effect of the middle and higher patches. A wider bandwidth at $6 \mathrm{GHz}$ is attributed to the maximum current in the rectangular stub, as shown in Fig. 8 (g). It can be concluded that by switching the states of $\mathrm{p}-\mathrm{i}-\mathrm{n}$ diodes, the change in surface current distribution results in multiband and multimode antenna (dual band and tri band modes).

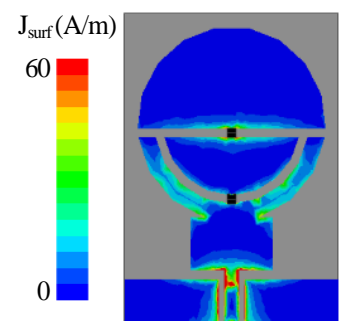

(a)

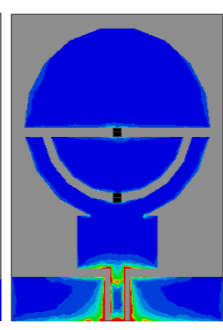

(b)

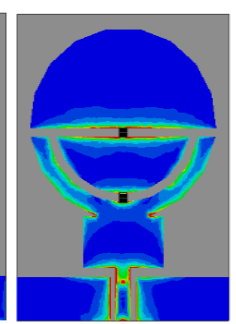

(c)

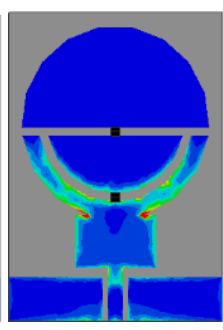

(d)

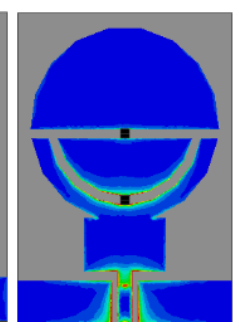

(e)

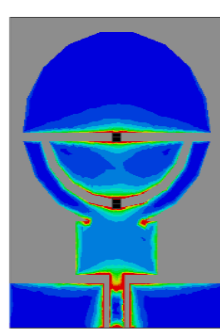

(f)

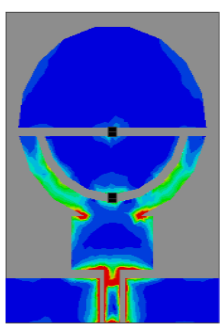

(g)

FIGURE 8. Current Desnity of proposed antenna at various frequencies. Case-00 (a) $3.5 \mathrm{GHz}$ (b) $8.5 \mathrm{GHz}$; Case-10 (c) $3.1 \mathrm{GHz}$ (d) $5.2 \mathrm{GHz}$ (e) 9 GHz; Case-11 (f) $2.1 \mathrm{GHz}$ (g) $6 \mathrm{GHz}$. 


\section{CONFORMABILITY ANAL YSIS}

The proper functionality of the antenna and performance consistency under the conformability condition is one of the key requirements for the flexible antennas. Therefore, the proposed antenna is tested under conformal conditions. Next, in the simulation, the antenna is bent in the $X$-axis and $Y$-axis on a cylinder having radius $(R) 25 \mathrm{~mm}$. A $25 \mathrm{~mm}$ radius is chosen by keeping in mind that the corner of the antenna did not touch each other. For measurement purposes, the proposed antenna is bent along a cylindrical shaped Styrofoam having a radius of 25 $\mathrm{mm}$, as depicted in Figure $9(\mathrm{a}-\mathrm{b})$.

Figure $10(\mathrm{a}-\mathrm{c})$ presents the comparison among simulated and measured results of magnitude of reflection coefficient $\left|S_{11}\right|$ (dB) under conformability condition. Figure 10 (a) depicts the results for case- 00 where the simulated results remained same as of unbent antenna while measured results show that antenna covers additional low band region. For case-10, the antenna exhibits similar results as that of unbending condition. A small and acceptable discrepancy was observed for higher bands, as illustrated in Figure 10 (b). Similarly, Figure 10 (c) presents the results for case-11. It can be observed from Figure 10 (c) that the measured results under conformability condition are in good agreement with that of the antenna under unbent condition. A small discrepancy among simulated and measured results due to imperfections in attachment of antenna with the cylindrical Styrofoam for the conformability analysis.

\section{E. FAR-FIELD ANAL YSIS}

To demonstrate far-field performance of the proposed antenna, far-field radiation pattern and gain were evaluated using electromagnetic simulator and measurements. However, for brevity, the numerically selected frequencies for case-00 at $3.5 \mathrm{GHz}$ and $8.5 \mathrm{GHz}$ where antenna exhibits nearly omnidirectional radiation pattern in principal $\mathrm{H}$-plane $\left(\theta=90^{\circ}\right)$ while a bidirectional radiation pattern is observed for E-plane $\left(\theta=0^{\circ}\right)$, as depicted in Fig.11 (a-b). The simulated value of gain is observed $3.21 \mathrm{dBi}$ and $5.23 \mathrm{dBi}$ while $3.17 \mathrm{dBi}$ and $5.21 \mathrm{dBi}$ measured gain at $3.5 \mathrm{GHz}$ and $8.5 \mathrm{GHz}$, respectively was achieved. Likewise, for case-10, the radiation patterns at 3.1 $\mathrm{GHz}, 5.2 \mathrm{GHz}$, and $9 \mathrm{GHz}$ are measured. It is observed that antenna exhibits omnidirectional radiation pattern in $H$-plane while a slightly tilted bidirectional radiation pattern is observed for $E$-plane for all selected frequencies, as illustrated in Fig. 11 (c - e). The simulated gain value at selected frequency of 3.1 $\mathrm{GHz}, 5.2 \mathrm{GHz}$ and $9 \mathrm{GHz}$ are $2.76 \mathrm{dBi}, 4.7 \mathrm{dBi}$, and $5.44 \mathrm{dBi}$, respectively. However, measured gain values of $2.7 \mathrm{dBi} @ 3.1$ $\mathrm{GHz}, 4.71 \mathrm{dBi} @ 5.2 \mathrm{GHz}$, and $5.31 \mathrm{dBi} @ 9 \mathrm{GHz}$ are observed. Similarly, for case-11, frequencies of $2.1 \mathrm{GHz}$ and 6 $\mathrm{GHz}$ are selected. Likewise, previous cases, the antenna exhibits omni-directional radiation pattern and bidirectional radiation pattern in principal $H$-plane $\left(\theta=90^{\circ}\right)$ and $E$-plane $(\theta=$ $\left.0^{\circ}\right)$, respectively. Moreover, the simulated gain value of $2.1 \mathrm{dBi}$ and $5.28 \mathrm{dBi}$ while measured gain value of $2.02 \mathrm{dBi}$ and 5.2

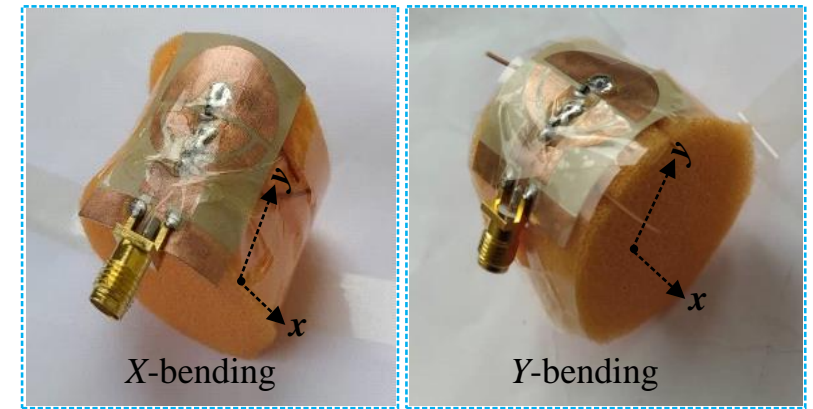

(a)

(b)

FIGURE 9. A photograph of the proposed antenna conformed on a clydrical styrofoam peformance analysis (a) bending along the $X$-axis (b) bending along the $Y$-axis.

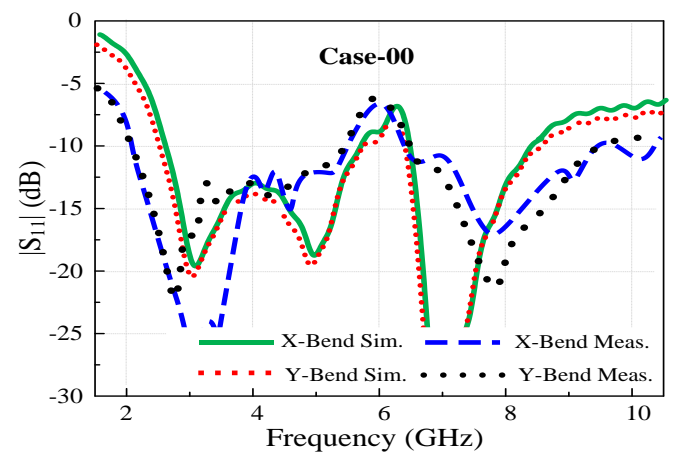

(a)

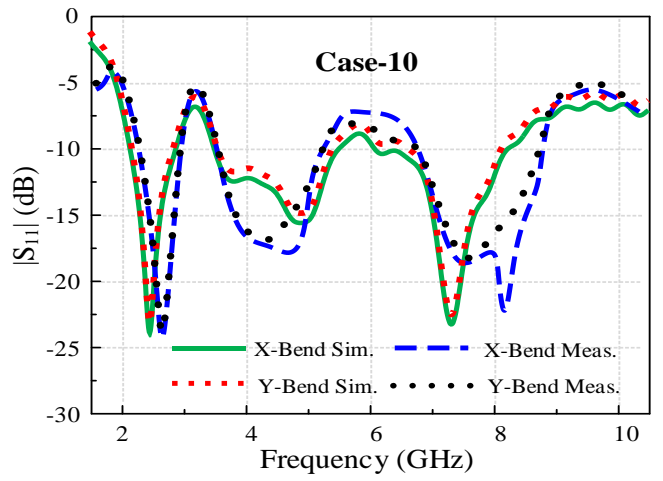

(b)

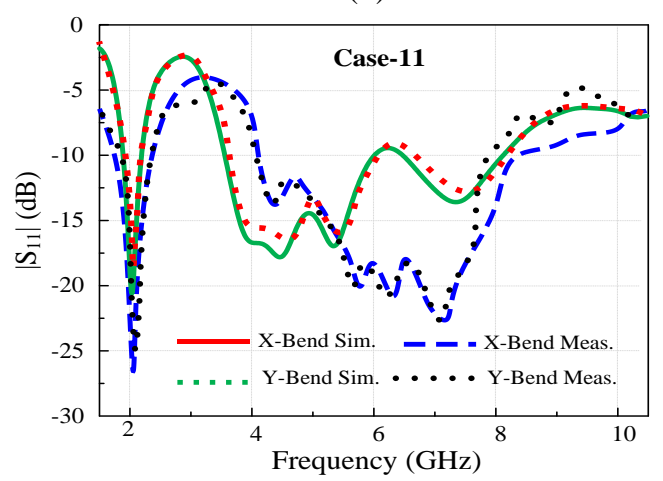

(c)

FIGURE 10. Conformability analysis comparison of the proposed antennana for various diode states (a) case-00 (b) case-10 (c) case-11. 


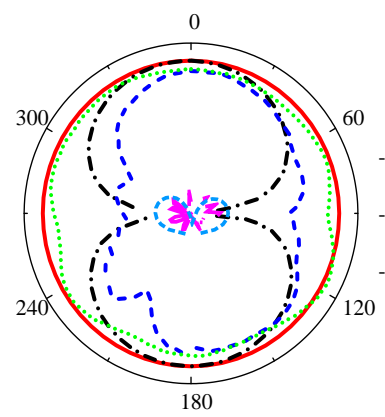

(a)

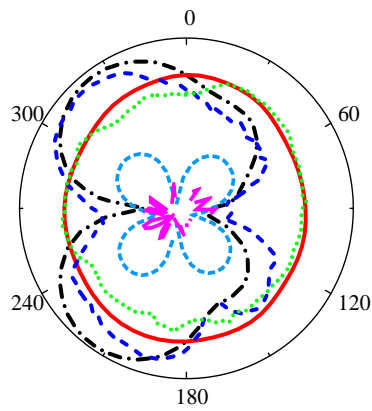

(e)

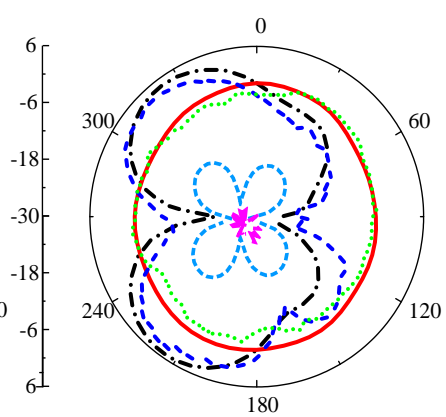

(b)

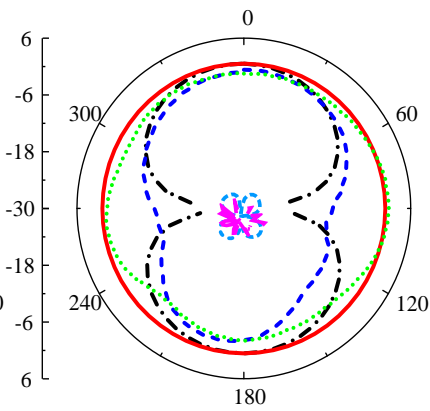

(f)

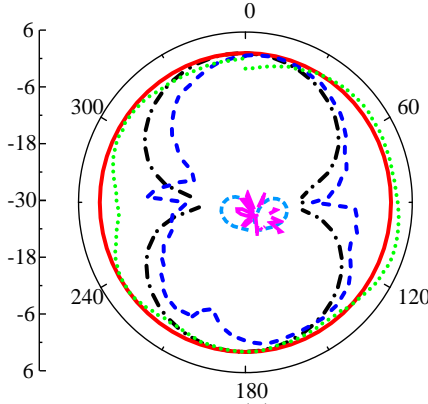

(c)

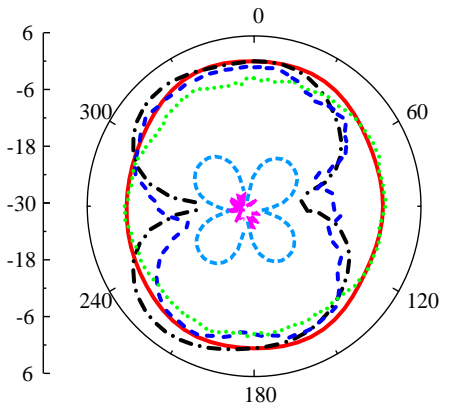

(g)

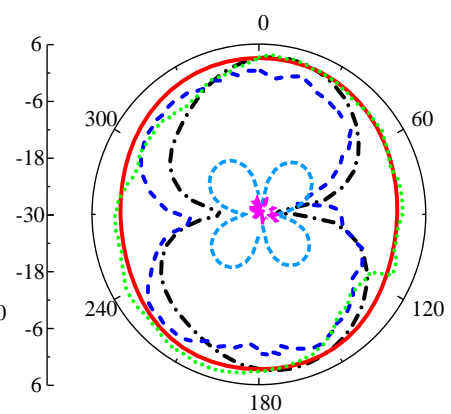

(d)

FIGURE 11. Comparison between simulated and measured radiation pattern. Case-00 (a) $3.5 \mathrm{GHz}$ (b) $8.5 \mathrm{GHz}$; Case-10 (c) $3.1 \mathrm{GHz}$ (d) $5.2 \mathrm{GHz}$ (e) 9 GHz; Case-11 (f) $2.1 \mathrm{GHz}(\mathrm{g}) 6 \mathrm{GHz}$.

TABLE I

COMPARISON OF SIMULATED AND MEASURED RESULTS OF THE PROPOSED ANTENNA

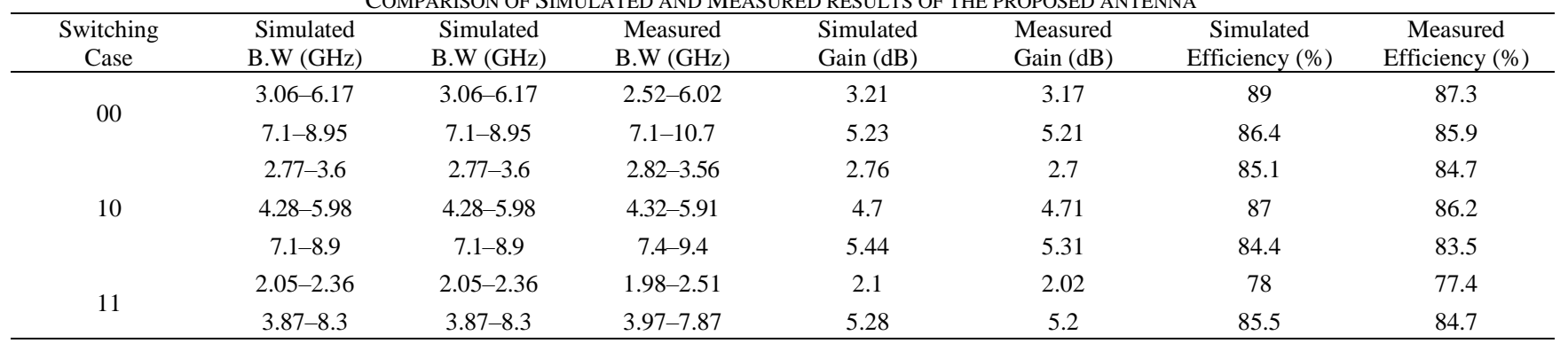

$\mathrm{dBi}$ at $2.1 \mathrm{GHz}$, and $7 \mathrm{GHz}$, respectively is achieved. It can be observed that at higher frequencies $(8 \mathrm{GHz}$ and $9 \mathrm{GHz}$ ), the radiation pattern is little deteriorated since the equivalent radiating area increased at high frequencies. Moreover, for all selected frequencies for various switching cases, the antenna exhibits minimum cross polarization of less than $-10 \mathrm{~dB}$, as depicted in Figure 11 (a-e). Overall, a fair agreement between simulated and measured results is observed. Table 1 presents the summary of the simulated and measured results of the proposed antenna.

\section{F. PERFORMANCE COMPARISON}

Table 2 presents a brief comparison of the proposed antenna with recently reported antennas for similar applications. The presented work outperforms the competitor works in terms of electrical size (with respect to lowest resonance) by showing at least $40.74 \%$ miniaturization and the total number of operating bands are seven. Besides this, the presented antenna covers the widest band ranging from $1.98 \mathrm{GHz}$ to $10.7 \mathrm{GHz}$ while the rest of the reported designs demonstrate antennas frequency reconfigurability within a close range. Moreover, good agreement between simulated and measured results in both conformal and non-conformal cases made this proposed antenna a potential candidate for heterogeneous applications possessing multiband antennas in modern flexible devices.

\section{CONCLUSION}

A miniaturized frequency reconfigurable flexible antenna operating at multiple on demand frequency mode is presented in this paper. Rectangular stub, semicircular, and rectangular slot are deployed as radiating parts to attain wideband and multiband operation. Two p-i-n diodes are used to connect the radiating parts of the antenna to resonate at different frequency bands. These sets of frequencies are achieved corresponding connection and disconnection of the radiating patch by using configuration of the $\mathrm{p}-\mathrm{i}-\mathrm{n}$ diodes. A 
TABLE II

PERFORMANCE COMPARISON OF THE PROPOSED ANTENNA WITH STATE-OF-THE-ART WORKS.

\begin{tabular}{|c|c|c|c|c|}
\hline Refs. & Antenna Size $\left(\lambda_{0}^{2}\right)$ & Operational Mode & $\begin{array}{c}-10 \mathrm{~dB} \\
\left|\mathrm{~S}_{11}\right| \mathrm{BW}(\mathrm{GHz})\end{array}$ & $\begin{array}{l}\text { Reconfigurability } \\
\text { Technique }\end{array}$ \\
\hline [21] & $0.27 \times 0.23$ & Tri-band & $4.19-4.48,5.98-6.4 \& 6.8-7 / 3.42-4,5.4-5.68 \& 6.8-7$ & Copper Tape \\
\hline [22] & $0.39 \times 0.37$ & $\begin{array}{l}\text { Dual band } \\
\text { Single band }\end{array}$ & $\begin{array}{c}3.9-4.53 \& 7.2-7.8 \\
4.7-5.4 / 3.9-4.6 / 5-6\end{array}$ & Copper Tape \\
\hline$[23]$ & $0.45 \times 0.23$ & $\begin{array}{l}\text { Single band } \\
\text { Dual band }\end{array}$ & $\begin{array}{c}2.34-2.5 \\
2.27-2.45 \& 3.5-3.77\end{array}$ & PIN Diode \\
\hline [24] & $0.36 \times 0.24$ & $\begin{array}{l}\text { Wideband } \\
\text { Dual band }\end{array}$ & $\begin{array}{c}2.18-3.52 \\
2.16-3.19 \& 3.55-3.795 / 2.15-2.77 \& 3.07-3.42\end{array}$ & PIN Diode \\
\hline$[25]$ & $0.69 \times 0.65$ & $\begin{array}{l}\text { Single band } \\
\text { Dual band }\end{array}$ & $\begin{array}{c}2.4-2.5 \\
2.35-2.52 \& 3.28-3.38\end{array}$ & PIN Diode \\
\hline$[26]$ & $0.46 \times 0.46$ & Single band & $2.3-2.68\left(\mathrm{BW}^{*}\right) / 2.26-3.9$ & Varactors \\
\hline [27] & $1.0 \times 0.97$ & $\begin{array}{l}\text { Single band } \\
\text { Dual band }\end{array}$ & $\begin{array}{c}1.65-2.5 \& 2.8-3.39 / 1.56-1.79 \& 2.5-3.17 / 2.28-2.72 \\
3.1-3.8\end{array}$ & PIN Diode \\
\hline $\begin{array}{c}\text { This } \\
\text { Work }\end{array}$ & $0.23 \times 0.16$ & $\begin{array}{l}\text { Dual band } \\
\text { Tri-band }\end{array}$ & $\begin{array}{c}2.52-6.02 \& 7.1-10.7 / 1.98-2.51 \& 3.97-7.87 \\
2.82-3.56,4.32-5.91 \& 7.4-9.4\end{array}$ & PIN Diode \\
\hline
\end{tabular}

$\lambda_{0}$ is free space wavelength at lowest resonating frequency, BW stands for bandwidth, $B W^{*}$ represent the total bandwidth covered by varactors diode

dual band operation for case-00, tri band for case-10 and dual band for case- 11 is achieved. The presented antenna attains at least $40.74 \%$ miniaturization in size and operates in more bands as compared to the most recent work reported in the literature. Moreover, a good agreement between simulated and measured results for both conformal and non-conformal scenarios make the proposed antenna a potential candidate for the devices operating in multiple allocated spectrum of Sband, Wi-Max, Wi-Fi, 5G sub-6-GHz, and ITU-band.

\section{REFERENCES}

[1] T. Li, Y. Dong, P. Fan and K. B. Letaief, "Wireless communications with RF-based energy harvesting: From Information Theory to Green Systems," IEEE Access, vol. 5, pp. 27538-27550, 2017.

[2] Guo, Y. Jay, Pei-Yuan Qin, Shu-Lin Chen, Wei Lin, and Richard W. Ziolkowski, "Advances in reconfigurable antenna systems facilitated by innovative technologies," IEEE Access, vol. 6, pp. 5780-5794, 2018.

[3] A. Zaidi, W. A. Awan, N. Hussain, and A. Baghdad, "A wide and triband flexible antennas with independently controllable notch bands for sub-6-GHz communication system," Radioengineering, vol. 29, no. 1 , pp. 44-51, 2020.

[4] H. Khaleel ed, Innovation in wearable and flexible antennas, Wit Press, Boston, USA, 2014.

[5] W.A. Awan, N. Hussain, and T.T. Le, "Ultra-thin flexible fractal antenna for $2.45 \mathrm{GHz}$ application with wideband harmonic rejection," AEU-Int J Electron Commun, vol. 110, pp. 152851-6, 2019.

[6] A. Smida, A. Iqbal, A. J. Alazemi, M. I. Waly, R. Ghayoula, and S Kim, "Wideband Wearable Antenna for Biomedical Telemetry Applications," IEEE Access, vol. 8, pp.15687-15694, 2020.

[7] A. Iqbal, A. J. Alazemi, and N. K. Mallat, "Slot-DRA-Based Independent Dual-Band Hybrid Antenna for Wearable Biomedical Devices," IEEE Access, vol. 7, pp.184029-184037, 2019.

[8] W. A. Awan, A. Zaidi, N. Hussain, A. Iqbal, and A. Baghdad, "Stub loaded, low profile UWB antenna with independently controllable notch-bands," Microw Opt Technol Lett, vol. 61, pp. 2447-54, 2019.

[9] F. Faisal, Y. Amin, Y. Cho and H. Yoo, "Compact and Flexible Novel Wideband Flower-Shaped CPW-Fed Antennas for High Data Wireless Applications," IEEE Trans Antennas Propag, vol. 67, no. 6, pp. 4184-8, 2019.

[10] A. Iftikhar et. al, "Changing the Operation of Small Geometrically Complex EBG-Based Antennas with Micron-Sized Particles That
Respond to Magneto-Static Fields,” IEEE Access, vol. 8, pp. 7895678964, 2020.

[11] A. Iftikhar et. al, "Characterization of Novel Structures Consisting of Micron-Sized Conductive Particles That Respond to Static Magnetic Field Lines for 4G/5G (Sub-6 GHz) Reconfigurable Antennas," Electronics, vol. 9, issue 6, 2020.

[12] Q. H. Abbasi, M. U. Rehman, X. Yang, A. Alomainy, K. Qaraqe and E. Serpedin, "Ultrawideband Band-Notched Flexible Antenna for Wearable Applications," IEEE Antennas Wirel Propag Lett, vol. 12, pp. 1606-1609, 2013.

[13] K. W. Lui, O. H. Murphy, and C. Toumazou, "A Wearable Wideband Circularly Polarized Textile Antenna for Effective Power Transmission on a Wirelessly-Powered Sensor Platform," IEEE Trans Antennas Propag, vol. 61, no. 7, pp. 3873-3876, July 2013.

[14] A. Arif, M. Zubair, M. Ali, M. U. Khan, and M. Q. Mehmood, "A compact, low-profile fractal antenna for wearable on-body WBAN applications," IEEE Antennas Wirel Propag Lett, vol. 18, no. 5, pp. 981-5, 2019

[15] B. Luadang, A. Sakonkanapong, S. Dentri, R. Pansomboon and C. Phongcharoenpanich, "NFC-Enabled Far-Field Antenna on PET Flexible Substrate for 3G/4G/LTE Mobile Devices," IEEE Access, vol. 7, pp. 171966-171973, 2019.

[16] R. B. Simorangkir, A. Kiourti and K. P. Esselle. "UWB wearable antenna with a full ground plane based on PDMS-embedded conductive fabric," IEEE Antennas Wirel Propag Lett., vol. 17, no. 3, pp.493-6, 2018.

[17] K. N. Paracha, S. K. A. Rahim, H. T. Chattha, S. S. Aljaafreh, S. U. Rehman, and Y. C. Lo, "Low-Cost Printed Flexible Antenna by Using an Office Printer for Conformal Applications," Int J Antennas Propag, vol. 2018, pp. 1-7, 2018.

[18] W. Li, Y. Hei, P. M. Grubb, X. Shi, and R. T. Chen, "Compact Inkjet-Printed Flexible MIMO Antenna for UWB Applications," IEEE Access, vol. 6, pp. 50290-50298, 2018.

[19] B. Mohamadzade, R. B. Simorangkir, R. M. Hashmi, Y. Chao-Oger, M. Zhadobov, and R. Sauleau "A Conformal Band-Notched Ultrawideband Antenna with Monopole-like Radiation Characteristics," IEEE Antennas Wirel Propag Lett, 2019.

[20] L. I. Balderas, A. Reyna, M. A. Panduro, C. Del Rio and A. R. Gutiérrez, "Low-Profile Conformal UWB Antenna for UAV Applications," IEEE Access, vol. 7, pp. 127486-127494, 2019.

[21] A. Ahmad, F. Arshad, S. I. Naqvi, Y. Amin, H. Tenhunen, and Jonathan Loo, "Flexible and Compact Spiral-Shaped Frequency Reconfigurable Antenna for Wireless Applications," IETE $J$ Research, pp. 1-8, 2018. 
[22] M. U. Hassan, A. Farzana, S. I. Naqvi, Y. Amin, and H. Tenhunen, "A Compact Flexible and Frequency Reconfigurable Antenna for Quintuple Applications," Radioengineering, vol. 26, no. 3, 2017.

[23] S. M. Saeed, C. A. Balanis and C. R. Birtcher, "Inkjet-Printed Flexible Reconfigurable Antenna for Conformal WLAN/WiMAX Wireless Devices," IEEE Antennas Wirel Propag Lett, vol. 15, pp. 1979-82, 2016.

[24] K. Saraswat and R. H. Ayyangar, "Flexible dual-band dual-polarised CPW-fed monopole antenna with discrete-frequency reconfigurability," IET Microw, Antennas Propag, vol. 13, no. 12, pp.2053-2060, 2019.

[25] S. M. Saeed, C. A. Balanis, C. R. Birtcher, A. C. Durgun and H. N. Shaman, "Wearable Flexible Reconfigurable Antenna Integrated With Artificial Magnetic Conductor," IEEE Antennas Wirel Propag Lett, vol. 16, pp. 2396-2399, 2017.

[26] R. B. V. B. Simorangkir,Y. Yang, K. P. Esselle, and B. A. Zeb, "A method to realize robust flexible electronically tunable antennas using polymer-embedded conductive fabric," IEEE Trans Antennas Propag, vol. 66, no. 1, pp. 50-58, 2017.

[27] H. F. Abutarboush and A. Shamim, "A reconfigurable inkjet-printed antenna on paper substrate for wireless applications," IEEE Antennas Wirel Propag Lett, vol.17, no. 9, pp.1648-1651, 2018.

[28] N. Hussain, M. Jeong, J. Park, and N. Kim, “A broadband circularly polarized Fabry-Perot resonant antenna using a single-layered PRS for 5G MIMO applications," IEEE Access, vol. 7, pp. 42897-42907, 2019.

[29] L.M Si, and X. Lv, "CPW-fed multi-band omni-directional planar microstrip antenna using composite metamaterial resonators for wireless communications," Prog Electromagn Res, vol. 83, pp. 133 46, 2008.

[30] R. P. Dwivedi and U. K. Kommuri. "CPW feed dual band and wideband antennas using crescent shape and T-shape stub for Wi-Fi and WiMAX application. Microw Opt Technol Lett, vol. 59, no. 10, pp. 2586-2591, 2017.

[31] W. C. Liu, C. M. Wu, and N. C. Chu, "A compact CPW-fed slotted patch antenna for dual-band operation," IEEE Antennas Wirel Propag Lett, vol. 9, pp. 110-113, 2010.

[32] M. J. Hua, P. Wang, Y. Zheng, and S. L. Yuan, "Compact tri-band CPW-fed antenna for WLAN/WiMAX applications," Electron Lett, vol. 49, no. 18, pp. 1118-1119, 2013.

[33] W. A. Awan, et al, "A miniaturized wideband and multi-band ondemand reconfigurable antenna for compact and portable devices," AEU-I J Electron Communi, vol. 122, pp. 153266, 2020.

[34] R. Z. Wu, P. Wang, Q. Zheng, and R. P. Li, "Compact CPW-fed triple-band antenna for diversity applications," Electron Lett, vol. 51, no. 10, pp. 735-6, 2015.

[35] Y. J. Li, Z. Y. Lu, and L. S. Yang, "CPW-fed slot antenna for medical wearable applications," IEEE Access, vol. 7, pp. 4210742112, 2019.

[36] C.A. Balanis, Advanced engineering electromagnetics, John Wiley \& Sons, 1999.

[37] S. I. Naqvi et al., "An Integrated Antenna System for 4G and Millimeter-Wave 5G Future Handheld Devices," IEEE Access, vol. 7, pp. 116555-116566, 2019. 